\title{
Observations of the effect of emergent vegetation on sediment resuspension under unidirectional currents and waves
}

\author{
R. O. Tinoco and G. Coco \\ Environmental Hydraulics Institute IH Cantabria, University of Cantabria, Santander, Spain \\ Correspondence to: R. O. Tinoco (tinocor@unican.es)
}

Received: 10 October 2013 - Published in Earth Surf. Dynam. Discuss.: 28 October 2013

Revised: 10 January 2014 - Accepted: 15 January 2014 - Published: 29 January 2014

\begin{abstract}
We present results from a series of laboratory experiments on a wave and current flume, where synchronous velocity and concentration measurements were acquired within arrays of rigid cylinders, representative of emergent vegetation and benthic communities, under different flow conditions. The density of an array of rigid cylinders protruding through a sandy bed affects the velocity field, sediment motion and resuspension thresholds when subjected to both unidirectional currents and regular waves. We compare the measured resuspension thresholds against predictions of sediment motion on non-obstructed flows over sandy beds. The results show that even if flow speeds are significantly reduced within the array, the coherent flow structures and turbulence generated within the array can enhance sediment resuspension depending on the population density.
\end{abstract}

\section{Introduction}

Aquatic vegetation and benthic populations alter their habitat in many different ways. Some species act as ecosystem engineers, modifying their habitats to guarantee their survival. We focus our study on the case of sparse to dense, rigid, randomly distributed arrays of emergent (protruding through the water free surface) elements, with scales representative of populations of tube worms and rigid vegetation, such as mangrove roots.

Two species would be directly represented by the designed arrays (Fig. 1): (1) European fan worm (Sabella spallanzanii), a filter feeding tube worm that creates canopies of feeding fans over the sediment, generally found in shallow subtidal areas, and (2) Black mangrove (Avicennia germinans), a subtropical woody shrub found in salt marshes.

The European fan worm is considered as an ecosystem engineer, building large platforms on the sea floor, creating sheltering areas for other organisms to grow and live, trapping particles, blocking light, improving oxygen supply in the sediment, altering current velocities, and stabilizing/destabilizing the sediment within and around the patch (Wallentinus and Nyberg, 2007; van Hoey et al., 2008). Black mangrove, living in intertidal areas, forms a network of pneumatophores, protruding through the water surface to allow for root respiration (Houck and Neill, 2009), forming an array that shelters the sediment and organisms around it.

The effects of such populations on sediment resuspension and deposition as a function of the properties of the array (i.e. density, porosity, solid volume fraction, individual spacing) are still not well understood (Eckman et al., 1981; Carey, 1983; Luckenbach, 1986; Graf and Rosenberg, 1997; Friedrichs et al., 2000; Coco et al., 2006), and one even finds contradictory results between field and experimental studies (Madsen et al., 2001), which emphasizes the need to distinguish between purely physical effects, as the ones we address, and purely biological effects, as the ones generated by macrophytes, microphytobenthos or macrofauna (LeHir et al., 2007). For example, an increase in turbulence by the physical presence of benthic organisms may enhance resuspension, but the mucus produced by those same organisms can form a protective film that suppresses it.

As Nikora (2010) points out, the growing new field of hydrodynamics of aquatic ecosystems needs to eliminate the multiple knowledge gaps between fluid mechanics, ecology and biomechanics. The work presented herein adds another 


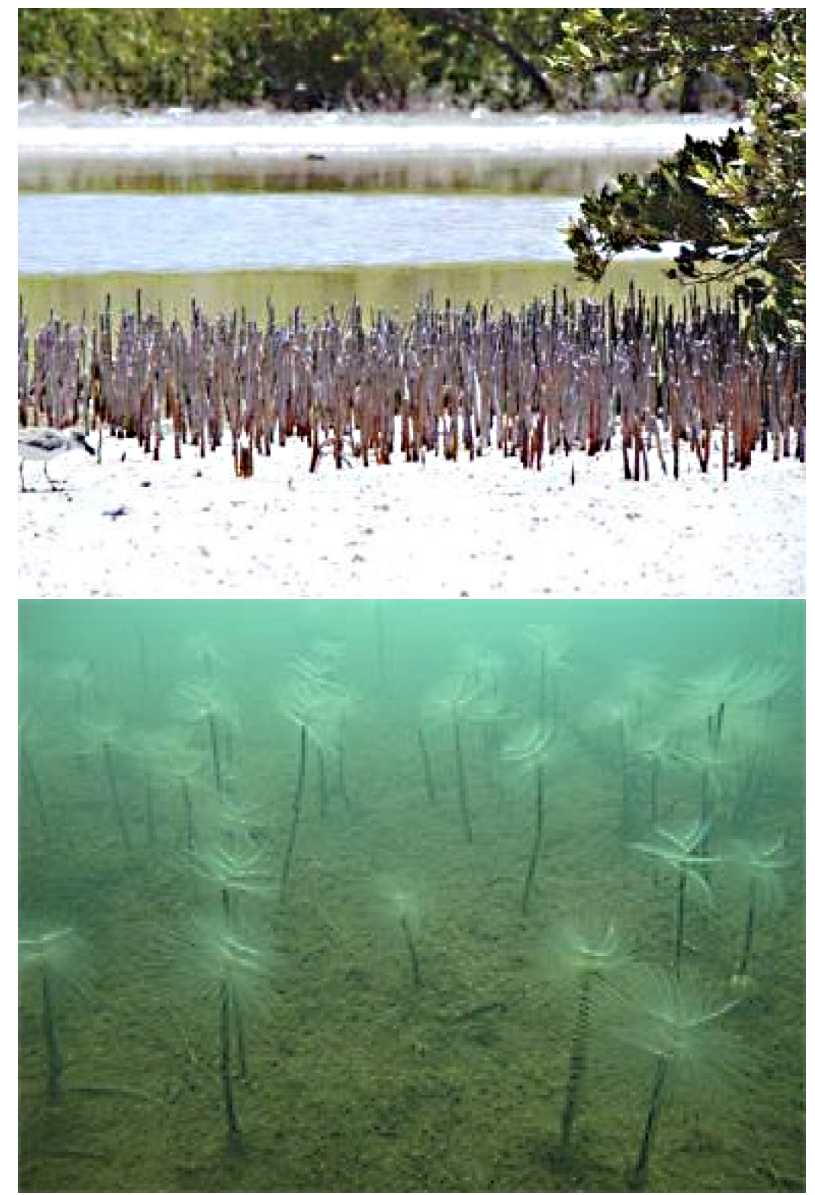

Figure 1. Species represented in the study. Black mangrove roots (left) and European fan worm (right). Pictures obtained from the USDA-NRCS and MESA websites, respectively.

step by incorporating biomorphodynamics as a critical component of the system.

\subsection{Thresholds of sediment motion for a flat, sandy bed}

There are many studies on critical stresses and velocities for sediment motion and resuspension on a flat, sandy bed under currents and waves (e.g. van Rijn, 2007 and references therein). However, literature on thresholds of motion for sediment within patches of vegetation or benthic populations is very scarce (see for example the laboratory work of Eckman et al., 1981 for unidirectional flows). We present herein a few of the existing criteria describing critical velocities and critical bed shear stress for sediment motion, as well as critical velocities for resuspension applicable to our investigated case. While those refer to non-populated beds, they will offer a starting point for comparison against the results from populated cases, allowing us to investigate the impact of the added physical processes induced by the presence of a vegetation patch.
We consider hereafter the formulations of van Rijn (1984) and Soulsby (1997) for critical velocities (a), the formulation of Soulsby (1997) for critical bed shear stress (b), and the resuspension threshold formulations of Soulsby (1997), van Rijn (1984), and Komar and Miller (1973) (c).

a. Critical velocities.

From van Rijn (1984):

$$
\begin{aligned}
& U_{\mathrm{cr}}=0.19 d_{50}^{0.1} \log _{10}\left(4 D / d_{90}\right) ; 100<d_{50}<500 \mu \mathrm{m} \\
& U_{\mathrm{cr}}=8.5 d_{50}^{0.6} \log _{10}\left(4 D / d_{90}\right) ; 500<d_{50}<2000 \mu \mathrm{m},
\end{aligned}
$$

where $D$ is the water depth, and $d_{50}$ and $d_{90}$ are the correspondent percentiles on the granulometric curve.

From Soulsby (1997):

$U_{\mathrm{cr}}=7\left(\frac{D}{d_{50}}\right)^{1 / 7}\left[g\left(s_{\rho}-1\right) d_{50} f\left(D_{*}\right)\right]^{1 / 2}$,

where

$s_{\rho}=\frac{\rho_{\mathrm{s}}}{\rho}=\frac{\text { density of the sediment }}{\text { density of the fluid }}$

$D_{*}=\left(\frac{g\left(s_{\rho}-1\right)}{v^{2}}\right)^{1 / 3} d_{50}$

$f\left(D_{*}\right)=\frac{0.30}{1+1.2 D_{*}}+0.055\left(1-e^{-0.020 D_{*}}\right)$

and $g$ is gravity, for values of $D_{*}>0.1$.

b. Critical bed shear stress.

From Soulsby and Whitehouse (Soulsby, 1997), we get values for critical bed shear stress from the Shields curve, and Soulsby fit to the Shields curve as

$$
\begin{aligned}
& \theta_{\mathrm{cr}}=\frac{0.24}{D_{*}}+0.055\left(1-e^{-0.020 D_{*}}\right) \\
& \theta_{\mathrm{cr}}=\frac{0.30}{1+1.2 D_{*}}+0.055\left(1-e^{-0.020 D_{*}}\right),
\end{aligned}
$$

where one can calculate

$$
\begin{aligned}
& \tau_{\mathrm{cr}}=\theta_{\mathrm{cr}} g\left(\rho_{\mathrm{s}}-\rho\right) d_{50} \\
& u_{*}=\left(\frac{\tau_{\mathrm{cr}}}{\rho}\right)^{1 / 2}
\end{aligned}
$$

such that a critical velocity can be estimated as

$$
U_{\mathrm{cr}}=\frac{u_{*}}{\kappa} \ln \left(\frac{z}{z_{0}}\right)
$$

using von Karman's $\kappa=0.41$, and estimating $z_{0}$ from Nikuradse's roughness:

$z_{0}=\frac{k_{\mathrm{s}}}{30}\left(1-\exp \left[\frac{-u_{*} k_{\mathrm{s}}}{27 v}\right]\right)+\frac{v}{9 u_{*}}$

with $k_{\mathrm{s}}=2.5 d_{50}$. 
c. Resuspension thresholds.

We use two criteria based on the settling velocity of the sand particles, $w_{\mathrm{s}}$, given empirically for natural sands as (Soulsby, 1997):

$$
w_{\mathrm{s}}=\frac{v}{d_{50}}\left[\left(10.36^{2}+1.049 D_{*}^{3}\right)^{1 / 2}-10.36\right]
$$

First, considering local turbulent bursts of sediment particles are lifted when (van Rijn, 1984):

$$
\begin{aligned}
& u_{* \mathrm{cr}}=\frac{4 w_{\mathrm{s}}}{D_{*}}, D_{*}<10 \\
& u_{* \mathrm{cr}}=0.4 w_{\mathrm{s}}, D_{*}>10 .
\end{aligned}
$$

Second, assuming no material can be suspended unless the friction velocity exceeds the settling velocity (Soulsby, 1997):

$u_{*} \geq w_{\mathrm{s}}$.

In the case of waves, the wave-orbital velocity theory from Komar and Miller (1973) has been shown to give accurate predictions for sand resuspension (Green, 1999). A critical orbital velocity, $U_{\mathrm{wc}}$ can be calculated from

$$
\frac{\rho U_{\mathrm{wc}}^{2}}{\left(\rho_{\mathrm{s}}-\rho\right) g d_{50}}=0.21\left(\frac{d_{\mathrm{w}}}{d_{50}}\right)^{1 / 2}
$$

where $d_{\mathrm{w}}=\frac{U_{\mathrm{wc}} T}{2 \pi}$ is the near-bottom orbital excursion.

\subsection{Studies on flow through aquatic vegetation}

Several research groups have studied flow through aquatic vegetation. Nepf (2012a) summarizes some of the experimental work done on rigid and flexible, emergent and submerged model vegetation subject to unidirectional currents on a flat, rigid bed. Nepf (2012b) highlights the challenges on the study of vegetated flows, specifically mentioning the need for a better understanding of sediment motion processes within vegetated regions, pointing out that (a) there is no reliable method to estimate bed stresses within the vegetation, (b) it is not known if bed shear stress is the only relevant parameter, (c) the role of the turbulence generated by the vegetation must be studied, (d) a new parameterisation is needed to account for spatial variability of the vegetation, and (e) the feedbacks between flow, vegetation and sediment are not yet understood.

A similar case occurs with studies on waves through vegetation. We find studies focusing on wave dissipation both through laboratory experiments (e.g. Fonseca and Cahalan, 1992), and field studies (e.g. Infantes et al., 2012), as well as analytical and numerical models to predict wave damping and velocities within the vegetated field (e.g. Kobayashi
Table 1. Relevant parameters for the studied arrays.

\begin{tabular}{cccccc}
\hline$n\left(\mathrm{~m}^{-2}\right)$ & $a\left(\mathrm{~m}^{-1}\right)$ & $\phi$ & $\langle s\rangle / d$ & $a D$ & $a d$ \\
\hline 0 & - & - & - & - & - \\
25 & 0.5 & 0.008 & 4.45 & 0.08 & 0.01 \\
150 & 3.0 & 0.047 & 1.70 & 0.48 & 0.06 \\
250 & 5.0 & 0.079 & 1.40 & 0.80 & 0.10 \\
\hline
\end{tabular}

et al., 1993; Maza et al., 2013), but none accounting for a mobile bed.

In terms of sediment studies, recent field and laboratory works on currents through submerged (Bouma et al., 2007; Borsje et al., 2011) and emergent vegetation (Follett and Nepf, 2012) share similar findings. Specifically, they found an increase in velocities and turbulent kinetic energy at the edges of the patch of vegetation, and increased scour with increased densities of the patch. The added effects of the mixing layer created at the plant-open-water interface for the submerged case might create differences in the observed deposition patterns. Follett and Nepf (2012) observed the maximum accumulation of sediment downstream of an emergent patch, while Bouma et al. (2007) reported maximum accumulations within the submerged patch. In the case of waves, to the authors knowledge, there are no experimental works on determination of sediment resuspension thresholds in the presence of arrays of rigid cylinders.

Our goal is to investigate how the presence of emergent arrays of sparse and dense rigid cylinders affects the onset of sediment resuspension under currents and under wave conditions. We record synchronous, collocated measurements of velocity and suspended sediment concentration to get mean and instantaneous values, to provide novel information to identify the role in sediment transport of turbulent quantities and high frequency fluctuations generated by the arrays.

\section{Laboratory experiments}

The experiments were conducted at the wave and current flume at the Environmental Hydraulics Institute of the University of Cantabria (IH Cantabria), a $54 \mathrm{~m}$ long, $2 \mathrm{~m}$ wide flume capable of running currents along $\left(0^{\circ}\right)$ and opposing $\left(180^{\circ}\right)$ the waves generated by a $2 \mathrm{~m}$ by $2 \mathrm{~m}$ piston-type wave maker with a maximum stroke of $2.0 \mathrm{~m}$. Two pumps run in parallel to generate flow in the flume, and can be set independently to run at frequencies, $f_{\mathrm{p}}$, between 20 and $50 \mathrm{~Hz}$.

An $18 \mathrm{~m}$ long, $0.20 \mathrm{~m}$ deep, sand bed was built, where a $6 \mathrm{~m}$-long array of randomly placed, rigid cylinders was located, as shown in Fig. 2. Water depth was set at $D=0.16 \mathrm{~m}$, to ensure emergent conditions at all times during the waves series. The sediment is well-sorted, $d_{50}=0.31 \mathrm{~mm}$, silica sand.

PVC cylinders, with a diameter $d=0.02 \mathrm{~m}$, were used to represent on a $1: 1$ scale either populations of tube worms 


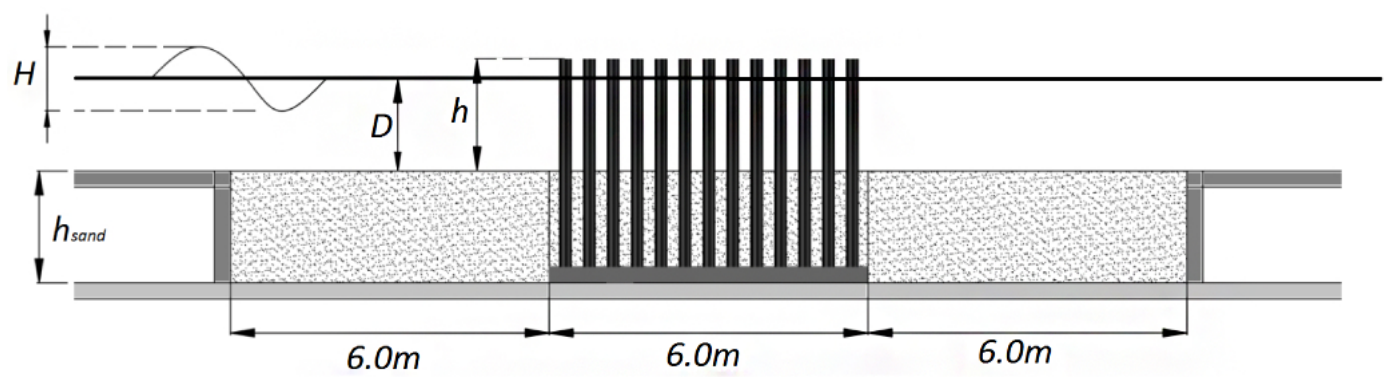

Figure 2. Random array of emergent cylinders, $d=2.0 \mathrm{~cm}$, protruding $h=21 \mathrm{~cm}$ above the sand bed. Water depth was set at $D=0.16 \mathrm{~m}$ for all cases.

(e.g. Sabella spallanzanii) and mangrove roots (e.g. Avicennia germinans). The arrays were designed by defining the number of elements per square meter, $n$, and a minimum distance, $s_{\min }=d$, allowed between the edges of adjacent cylinders. The $0.40 \mathrm{~m}$ long cylinders were individually attached with screws to six $1 \mathrm{~m}$ long, $2 \mathrm{~m}$ wide PVC plates fitted to the bottom of the flume and later covered by the $0.20 \mathrm{~m}$-deep sand bed, creating the array of cylinders protruding $0.21 \mathrm{~m}$ above the bed. Three densities were considered to represent a sparse, intermediate and dense population: $n=\{25,150,250\} \mathrm{m}^{-2}$. The study began with the densest case, and selected cylinders were removed to achieve progressively lower densities. Once a cylinder was removed, it was not possible to install it again, such that a single random configuration was used for each density. Three relevant parameters of the array are calculated for each density: (1) volumetric frontal area of the array, $a\left(\mathrm{~m}^{-1}\right)$, given as the frontal area of the cylinders, $A_{\mathrm{f}}=N_{\text {cylinders }} \mathrm{d} D$, per volume, $V=A_{\text {planform }} D$, which reduces to $a=n d$; (2) solid volume fraction $\phi()$, given as the ratio between the volume of solids and fluid volume, or $\phi=n \pi d^{2} / 4$ for emergent cylinders; and (3) the mean separation between cylinders, $\langle s\rangle(\mathrm{m})$, given in non-dimensional form as $\langle s\rangle / d$ (Table 1). To ensure fully covering the range from sparse to dense conditions, the selected densities satisfy criteria proposed by Friedrichs et al. (2000), defining dense arrays as those with values of $\phi>0.045$, and by Nepf (2012a), considering sparse arrays with $a D \ll 0.1$, and dense if $a D \gg 0.1$. We chose the intermediate density, $n=150 \mathrm{~m}^{-2}$ to be in the limit between sparse and dense arrays.

Acoustic Doppler velocimeters (ADV - Nortek Vectrino) and optical backscatter sensors (OBS - Seapoint turbidity meter, SeaPoint Sensors Inc.), recording at a sampling frequency $f_{\mathrm{s}}=50 \mathrm{~Hz}$, were used to measure synchronous records of velocities and concentrations, respectively. For the emergent case presented herein, ADVs and OBSs were located $5 \mathrm{~cm}$ above the sand bed, at the beginning $\left(x_{\mathrm{c}}=0 \mathrm{~m}\right)$ and at the middle $\left(x_{\mathrm{c}}=3 \mathrm{~m}\right)$ of the array. The distance of $5 \mathrm{~cm}$ above the bed was determined by the physical dimensions of the instruments, such that the sensors were not in contact with the bottom and would not be buried in the sand during the experiments. A total of 19 capacitive wave gauges (Akamina technologies) were used for free surface measurements along the length of the flume.

For the study on unidirectional currents, different flow rates were ran for each array density, increasing the frequency of one of the pumps from $f_{\mathrm{p}}=20-50 \mathrm{~Hz}$. The sand was flattened manually before each series, using a floor squeegee for the non-populated areas and a cold water high pressure cleaner within the cylinders array, flattening again after the maximum velocity was studied. The range of velocities considered falls in a range of Reynolds numbers $R e_{D}=$ $U D / v<4 \times 10^{4}$, and $R e_{d}=U d / v<5 \times 10^{3}$ for all cases. Flow remained subcritical, with $F r<0.2$ for all cases.

For studies on waves, five cases with regular waves were conducted for each density, with a constant period $T=2.5 \mathrm{~s}$ and nominal wave height $H=0.01-0.05 \mathrm{~m}$. For a water depth $D=0.16 \mathrm{~m}$, the dispersion relationship yields a wavelength $\lambda=3.08 \mathrm{~m}$, fitting two wavelengths within the $6 \mathrm{~m}$ array. Series of 50 waves were generated for each $H$. The maximum values presented are for $H=0.05 \mathrm{~m}$, given that breaking occurred at $H=0.06 \mathrm{~m}$.

\section{Results}

\subsection{Currents}

For each density, the series was stopped once scour became noticeable (see Figs. 3 and 4). Once sand starts accumulating behind the cylinders and bedforms start to appear within the array, vortices are generated in the now perturbed bed, enhancing resuspension as compared to a flat bed case. Once such a state is reached and the threshold values have been exceeded, the series has been stopped. As seen in Fig. 5, as the density of the array increased, scour appeared for lower velocities, thus reducing the range of velocities studied for the denser cases (fewer data points for $n=250 \mathrm{~m}^{-2}$ in Fig. 5).

Time averaged longitudinal, $x$ velocities are shown in Fig. 5 (left) for the same flow conditions for each array density. The measured response by the OBS for all densities studied are also shown in Fig. 5 (right). We notice an abrupt jump in the concentration values for the two denser cases 
Table 2. Wave parameters for all densities at locations $x_{\mathrm{c}}=0 \mathrm{~m}$ and $x_{\mathrm{c}}=3 \mathrm{~m}$.

\begin{tabular}{rcccccccc}
\hline & \multicolumn{9}{c}{$x_{\mathrm{c}}=0 \mathrm{~m}$} \\
\cline { 2 - 9 }$n\left(\mathrm{~m}^{-2}\right)$ & $\begin{array}{c}H_{\mathrm{m}} \\
(\mathrm{m})\end{array}$ & $\begin{array}{c}U_{\mathrm{w}+} \\
\left(\mathrm{m} \mathrm{s}^{-1}\right)\end{array}$ & $\begin{array}{c}U_{\mathrm{w}-} \\
\left(\mathrm{m} \mathrm{s}^{-1}\right)\end{array}$ & $\begin{array}{c}d_{\mathrm{w}} \\
(\mathrm{m})\end{array}$ & $\begin{array}{c}H_{\mathrm{m}} \\
(\mathrm{m})\end{array}$ & $\begin{array}{c}U_{\mathrm{w}+} \\
\left(\mathrm{m} \mathrm{s}^{-1}\right)\end{array}$ & $\begin{array}{c}U_{\mathrm{w}-} \\
\left(\mathrm{m} \mathrm{s}^{-1}\right)\end{array}$ & $\begin{array}{c}d_{\mathrm{w}} \\
(\mathrm{m})\end{array}$ \\
\hline 0 & 0.013 & 0.076 & -0.093 & 0.030 & 0.015 & 0.083 & -0.098 & 0.033 \\
0 & 0.029 & 0.143 & -0.067 & 0.057 & 0.031 & 0.120 & -0.162 & 0.048 \\
0 & 0.047 & 0.228 & -0.076 & 0.091 & 0.047 & 0.188 & -0.127 & 0.075 \\
0 & 0.062 & 0.289 & -0.092 & 0.115 & 0.060 & 0.221 & -0.198 & 0.088 \\
0 & 0.079 & 0.304 & -0.112 & 0.121 & 0.079 & 0.245 & -0.245 & 0.098 \\
25 & 0.014 & - & - & - & - & - & - & - \\
25 & 0.031 & 0.128 & -0.068 & 0.051 & 0.029 & 0.131 & -0.047 & 0.052 \\
25 & 0.050 & 0.224 & -0.062 & 0.089 & 0.044 & 0.200 & -0.084 & 0.079 \\
25 & 0.068 & 0.293 & -0.077 & 0.116 & 0.055 & 0.222 & -0.163 & 0.088 \\
25 & 0.078 & 0.313 & -0.081 & 0.125 & 0.063 & 0.257 & -0.171 & 0.102 \\
150 & 0.012 & 0.068 & -0.078 & 0.027 & 0.013 & 0.071 & -0.086 & 0.028 \\
150 & 0.029 & 0.141 & -0.134 & 0.056 & 0.024 & 0.086 & -0.076 & 0.034 \\
150 & 0.047 & 0.233 & -0.129 & 0.093 & 0.032 & 0.113 & -0.098 & 0.045 \\
150 & 0.064 & 0.288 & -0.168 & 0.114 & 0.038 & 0.127 & -0.126 & 0.050 \\
150 & 0.070 & 0.289 & -0.157 & 0.115 & 0.042 & 0.148 & -0.137 & 0.059 \\
250 & 0.015 & 0.047 & -0.042 & 0.019 & 0.014 & 0.053 & -0.040 & 0.021 \\
250 & 0.031 & 0.106 & -0.078 & 0.042 & 0.022 & 0.102 & -0.038 & 0.041 \\
250 & 0.047 & 0.214 & -0.085 & 0.085 & 0.027 & 0.130 & -0.053 & 0.052 \\
250 & 0.062 & 0.259 & -0.122 & 0.103 & 0.031 & 0.137 & -0.082 & 0.055 \\
250 & 0.078 & 0.291 & -0.128 & 0.116 & 0.036 & 0.144 & -0.101 & 0.057 \\
\hline & & & & & & & &
\end{tabular}

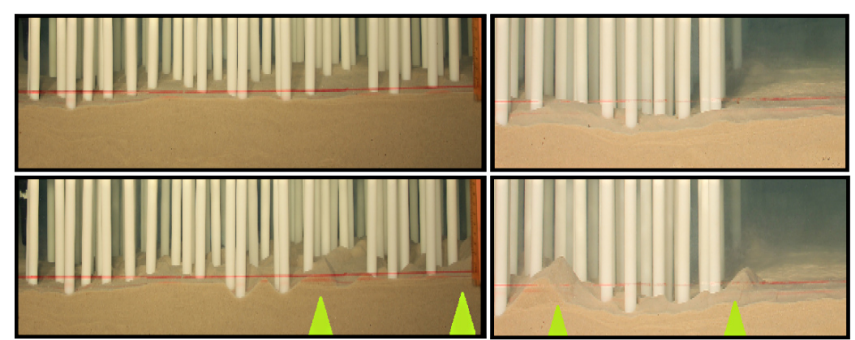

Figure 3. Side view: $n=150 \mathrm{~m}^{-2}$, upstream (left) and downstream (right) edge of the array, before (up) and after (down) 5 min running at $f_{\mathrm{p}}=30 \mathrm{~Hz}$. Notice the scour and bedforms forming within the array at the up- and downstream sections (as pointed by the green arrows). Red line is the initial reference for the bed level. Notice the factor of 2 increase in the vertical scale.

once a critical value is reached, in contrast with the trend seen for the non-populated case.

Figure 6 (left) shows the values of turbulent kinetic energy, $k=\frac{1}{2}\left(u^{\prime 2}+v^{\prime 2}+w^{\prime 2}\right)$, for all densities and flow rates studied, with higher values being reached for the denser cases at very low speeds compared to the non-populated case. We also notice in Fig. 6 (right) that even when the highest speeds for the non-populated case reach similar values of $k$ as the densest array at lower speeds, the recorded concentration of suspended sediment is much lower.

As noticed in Fig. 7, large fluctuations were observed in the transverse, $y$ velocities, corresponding with transverse

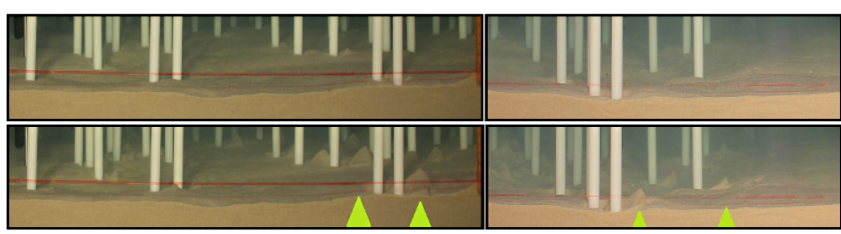

Figure 4. Side view: $n=25 \mathrm{~m}^{-2}$, upstream (left) and downstream (right) edge of the array, before (up) and after (down) 5 min running at $f_{\mathrm{p}}=30 \mathrm{~Hz}$. Notice the scour and bedforms forming within the array at the up- and downstream sections (as pointed by the green arrows). Red line is the initial reference for the bed level. Notice the factor of 2 increase in the vertical scale.

standing waves generated by the array of cylinders. As the shredding frequency of the cylinders approaches a natural frequency of the flume, the corresponding standing wave appears (see Tinoco and Cowen, 2013).

The natural frequencies, $f$, of a flume of width $B$, can be calculated for each wave mode $m$ (see Tinoco and Cowen, 2013 for details), as $f=\frac{1}{2 \pi}\left(\frac{\pi m}{B} g \tanh \left(\frac{\pi m B}{D}\right)\right)^{1 / 2}$. In the case of our flume, for the first four modes, $m=\{1,2,3,4\}$, we have $f(m)=\{0.62,0.88,1.08,1.25\} \mathrm{Hz}$. By obtaining the frequency spectra of all concentration and velocity records, we notice clear peaks at the frequencies corresponding to modes 2 and 3 at lower velocities, and a clear peak corresponding to mode 3 as we increase the flow. Figure 7 shows spectra for 

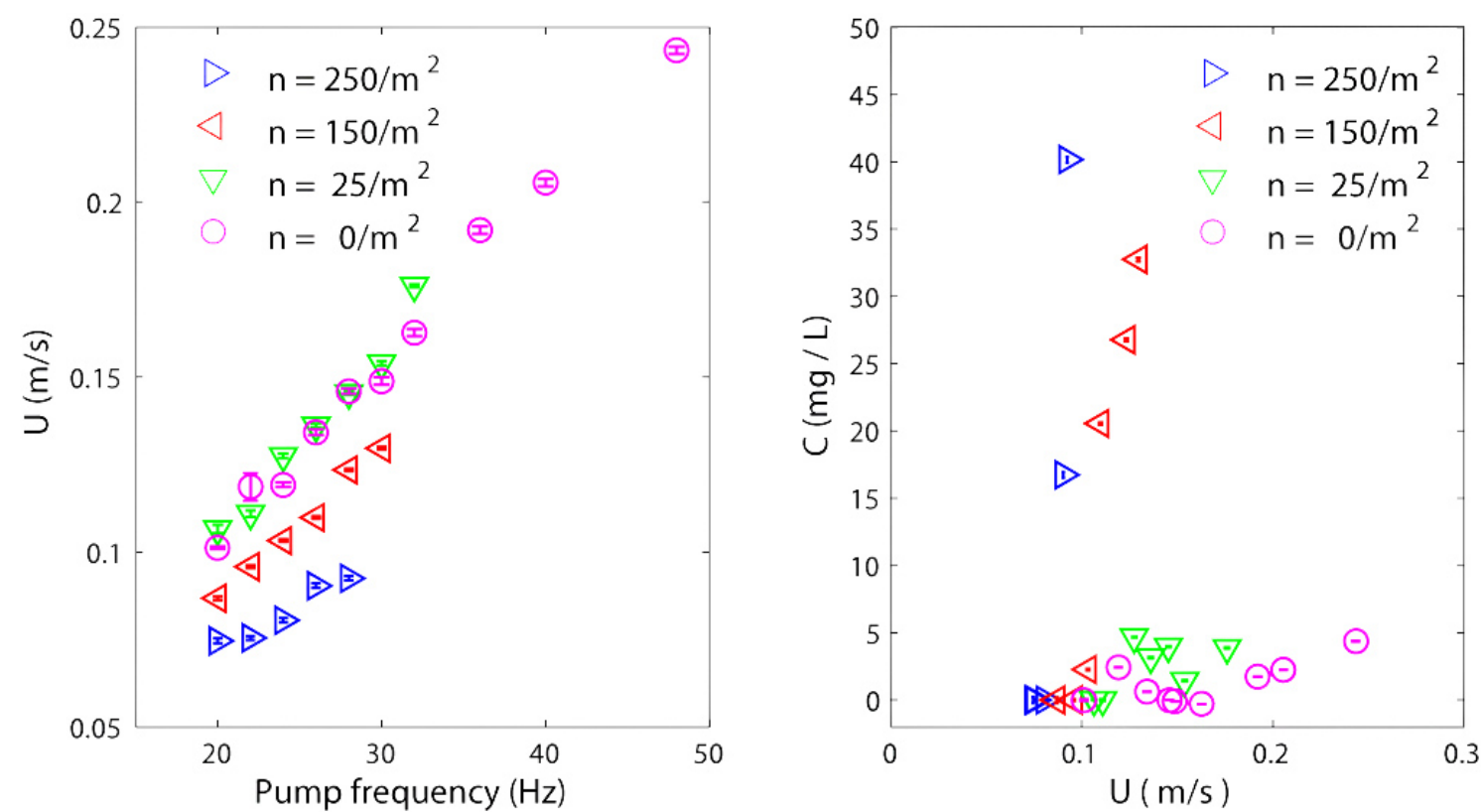

Figure 5. Left: mean longitudinal $x$ velocities as a function of the pump frequency. Right: mean suspended sediment concentrations recorded at each velocity for all densities. Velocities measured at the center of the array $x_{\mathrm{c}}=3 \mathrm{~m}$, at $z=0.05 \mathrm{~m}$ above the bed. Vertical error bars for the $95 \%$ CI. Notice the range of velocities studied decreased for the denser cases to avoid disruptions in the bed.
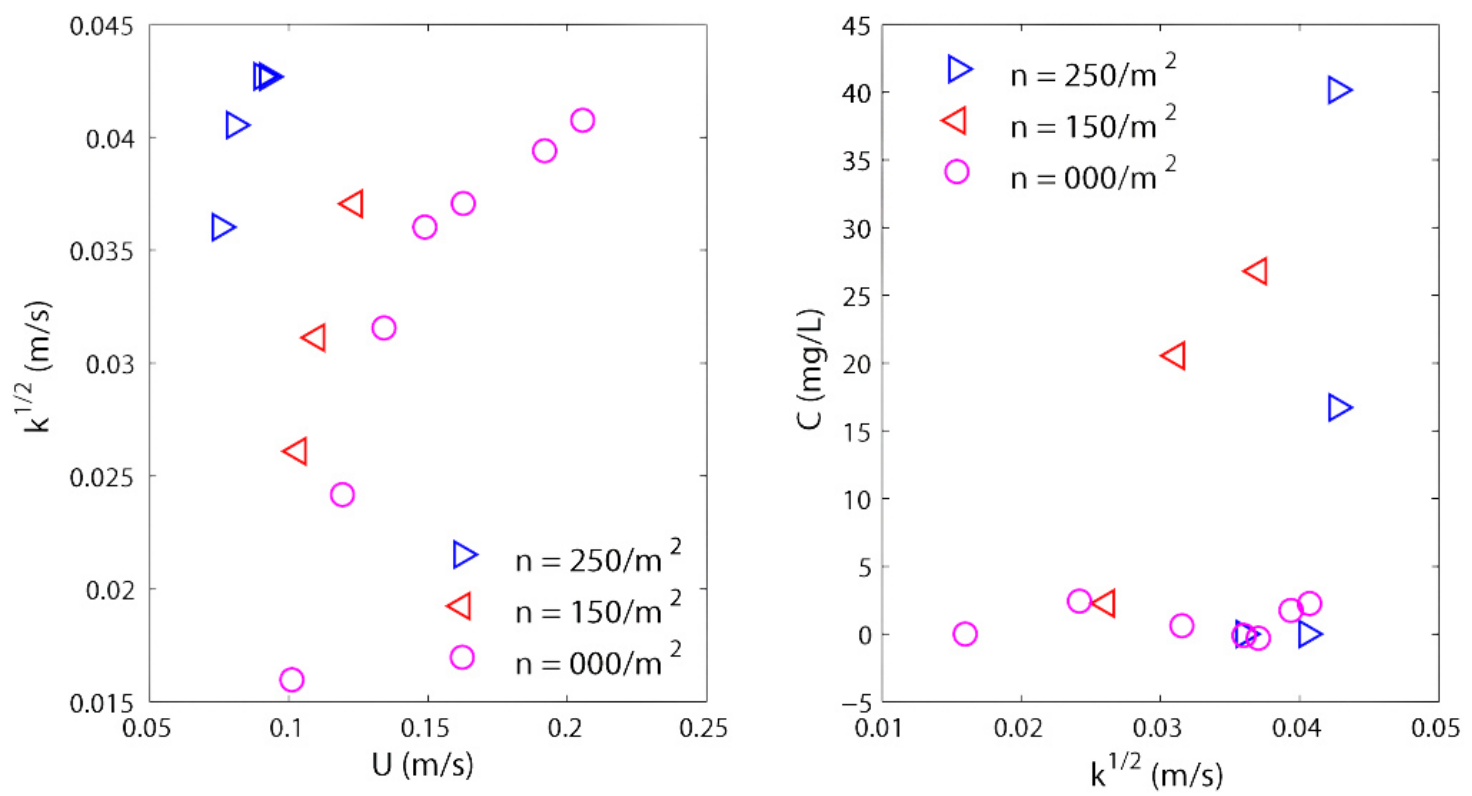

Figure 6. Turbulent kinetic energy, $k$, as a function of mean velocity $U$ (left), and concentrations against $k$ for all densities (right). Measurements at the center of the array $x_{\mathrm{c}}=3 \mathrm{~m}$, at $z=0.05 \mathrm{~m}$ above the bed. 

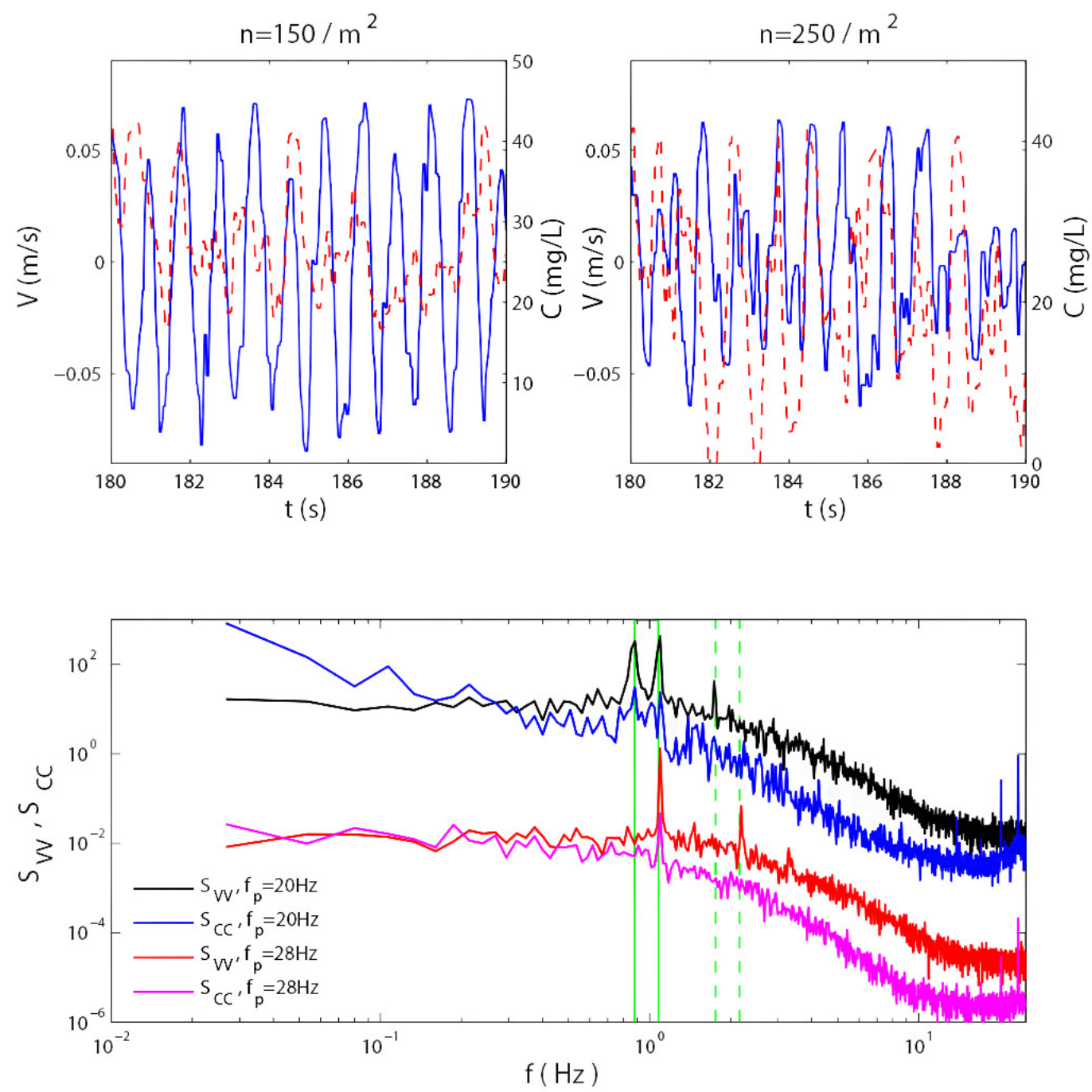

Figure 7. Top: transverse velocity (blue solid line) and concentration (red dashed line) fluctuations due to transverse standing waves generated with increasing density. Bottom: velocity and concentration spectra for $n=250 \mathrm{~m}^{-2}$, at the minimum and maximum flow rates considered. Vertical solid green lines show the expected frequencies for modes $2(0.88 \mathrm{~Hz})$ and $3(1.08 \mathrm{~Hz})$ of the flume, and dashed green lines show twice such frequencies. Actual magnitudes of $S_{\mathrm{vv}}$ and $S_{\mathrm{CC}}$ have been altered to improve visualisation.

the densest case, $n=250 \mathrm{~m}^{-2}$, highlighting the match of frequencies for the slowest and fastest flow conditions studied.

Figure 7 shows that the OBS not only captured the bulk increase in concentration of suspended sediment due to the oscillations in $V$, but also the concentration oscillations they caused.

\subsection{Waves}

The measured mean wave heights $H_{\mathrm{m}}$ at relevant $x$ locations: near the paddle $\left(x_{\mathrm{c}}=-16 \mathrm{~m}\right)$, at the beginning of the sand section $\left(x_{\mathrm{c}}=-6 \mathrm{~m}\right)$, and within the array of cylinders $\left(x_{\mathrm{c}}=\{0,1,2,3,5,6\} \mathrm{m}\right)$, are shown in Fig. 8 . To build the sand bed, ramps were built on each side of the flume, changing its initial configuration and resulting in the wave shoaling ob- served in Fig. 8. Reflection effects from the downstream end of the flume were more evident in the non-populated case (noticed by the fluctuations in $H_{\mathrm{m}}$ ), since the cylinders were very efficient also at damping reflected waves.

While wave dissipation is not the main focus of our work, the effect of the array at dissipating the incoming waves is evident, with reductions of more than $50 \%$ of the approaching wave height for the densest cases (Fig. 8). With energy being dissipated as the wave advances through the array, the bottom shear stresses also decrease, reducing resuspension in favour of sediment deposition. Figures 9 and 10 show the upand downstream edges of the array before and after a series of 50 waves. Scour and bedforms are clearly present at the upstream section, whereas the downstream area shows little, if any, bed disruptions. This behaviour is contrary to the one 

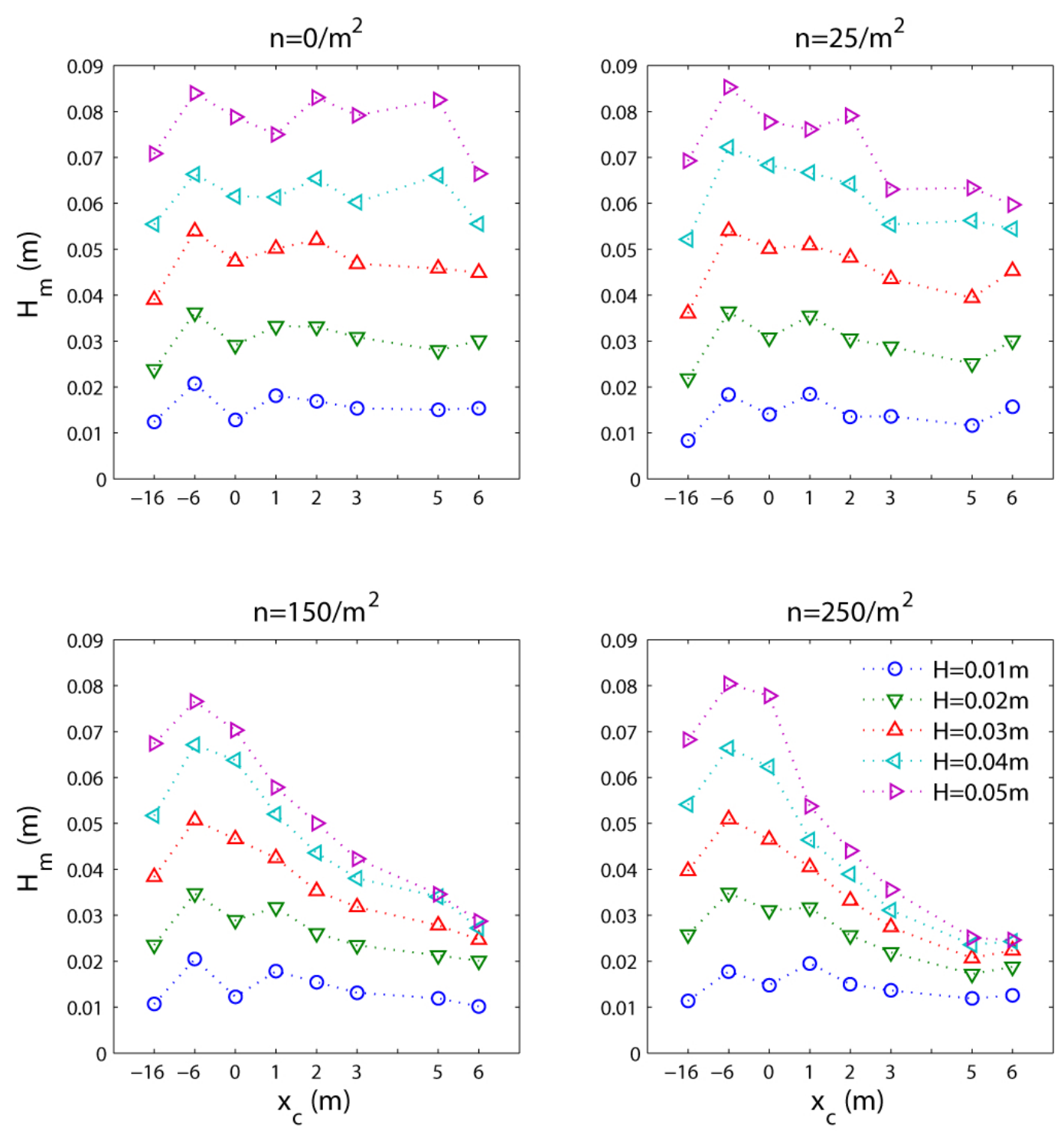

Figure 8. Mean wave height, $H_{\mathrm{m}}$, recorded along the flume, from the nearest sensor to the wave maker $\left(x_{\mathrm{c}}=-16 \mathrm{~m}\right)$, to the beginning of the sand bed $\left(x_{\mathrm{c}}=-6 \mathrm{~m}\right)$ to the end of the array $\left(x_{\mathrm{c}}=6 \mathrm{~m}\right.$. Notice negative $x_{\mathrm{c}}$ coordinates are not in scale.

observed for currents, where the array effectively slows down the flow, yielding smaller velocities at the upstream section than at the downstream exit.

To account for the relationship between orbital velocities within the array and the measured concentrations, the maximum velocities in both directions $\left(U_{\mathrm{w}+}\right.$ and $\left.U_{\mathrm{w}-}\right)$ were obtained from the records. The near-bottom orbital excursion, $d_{\mathrm{w}}=\frac{U_{\mathrm{w}+} T}{2 \pi}$, was calculated using $U_{\mathrm{w}+}$ as the near-bottom orbital speed (Table 2). The relationship between the near bottom orbital speed and recorded values of suspended sediment concentration appears in Figs. 11 and 12. From the results from the station at $x_{\mathrm{c}}=3 \mathrm{~m}$ it is clear the difference between sparse $\left(n=0,25 \mathrm{~m}^{-2}\right)$ and dense $\left(n=150,250 \mathrm{~m}^{2}\right)$ arrays, with the data almost collapsing into two distinctive curves in Fig. 12.

We also compare the behaviour of free surface elevation and concentration for the non-populated and the densest case, at the two instrumented locations (Figs. 13 and 14). The correlation between the time series is evident, and the amount of suspended sediment increases as the wave travels through the sand bed for $n=0$, while the opposite occurs for the densest case. The effect was clearly visible during the experiments, with a cloud of sediment being lifted as the wave encountered the array. Even when monochromatic, sinusoidal waves were generated at the paddle, shoaling due to the ramps built to contain the sand, and the changes in the bottom material, concrete-steel-sand, result in significant wave transforma- 


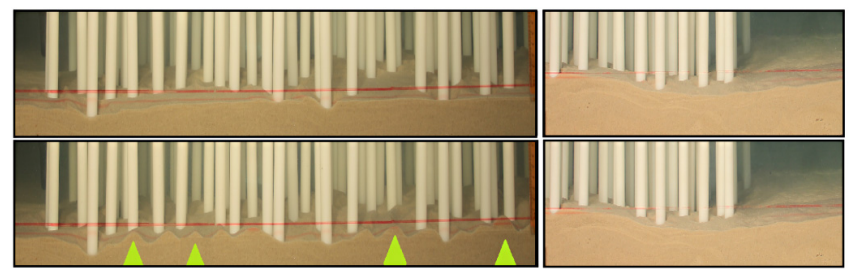

Figure 9. Side view: upstream (left) and downstream (right) edge of the array, before (up) and after (down) 50 waves, $H=0.05 \mathrm{~m}, T=$ $2.5 \mathrm{~s}, n=150 \mathrm{~m}^{-2}$. Notice the scour and bedforms forming within the array at the upstream section (as pointed by the green arrows) while the downstream section remains unaltered. Notice the factor of 2 increase in the vertical scale.

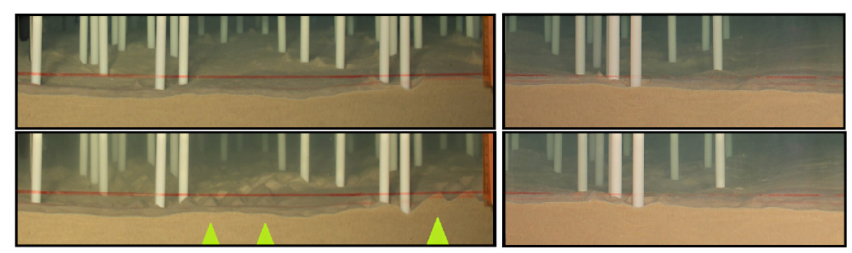

Figure 10. Side view: upstream (left) and downstream (right) edge of the array, before (up) and after (down) 50 waves, $H=0.05 \mathrm{~m}, T=$ $2.5 \mathrm{~s}, n=25 \mathrm{~m}^{-2}$. Notice the scour and bedforms forming within the array at the upstream section (as pointed by the green arrows) while the downstream section remains unaltered. Notice the factor of 2 increase in the vertical scale.

tion. In Fig. 13 it is noticed the skewed, saw-tooth shape nature of the waves as they reach the middle of the array $\left(x_{\mathrm{c}}=3 \mathrm{~m}\right)$. The effects of velocity and acceleration skewness on sediment transport are an active area of research and, as pointed out by Hoefel and Elgar (2003) and van der A et al. (2010), are not well understood. However, it is known that as the waves enter shallow water (representative of the habitat of our considered species), sinusoidal waves can transform into skewed, saw-tooth shaped waves with a sharp front as the ones observed in Fig. 13 leading to higher onshore velocities that may result in onshore net transport. Since we do not have enough data to compare different skewness and asymmetry conditions, we limit the study to the measured velocities under the achieved wave conditions and their respective suspended sediment concentrations.

To look for similar trends in the recorded velocities and concentrations, the frequency spectra are calculated for the $n=0$ and $n=250 \mathrm{~m}^{-2}$ cases, as shown in Fig. 15. By comparing the densest against the non-populated case, we notice the passing of energy towards higher frequencies, as eddies break down to smaller scales through the array and energy passes from wave scales to individual cylinder scales.
Table 3. Measured critical velocities for currents, $U_{\mathrm{c}}$, and critical orbital velocities, $U_{\mathrm{wc}}$, according to the measurements of suspended sediment concentration at $z=0.05 \mathrm{~m}$ for all densities at $x_{\mathrm{c}}=3 \mathrm{~m}$.

\begin{tabular}{rcc}
\hline$n\left(\mathrm{~m}^{-2}\right)$ & $U_{\mathrm{c}}\left(\mathrm{m} \mathrm{s}^{-1}\right)$ & $U_{\mathrm{wc}}\left(\mathrm{m} \mathrm{s}^{-1}\right)$ \\
\hline 250 & 0.080 & 0.063 \\
150 & 0.096 & 0.071 \\
25 & 0.111 & 0.131 \\
0 & 0.163 & 0.120
\end{tabular}

Table 4. Theoretical critical values for sediment motion (SM) and resuspension $(R)$.

\begin{tabular}{lc}
\hline Criteria & $U_{\mathrm{c}}\left(\mathrm{m} \mathrm{s}^{-1}\right)$ \\
\hline van Rijn 1984 (SM) & 0.297 \\
Soulsby 1997 (SM) & 0.259 \\
Soulsby and Whitehouse 1997 (SM) & 0.312 \\
van Rijn 1984 $(R)$ & 0.532 \\
Soulsby 1997 $(R)$ & 0.917 \\
\hline
\end{tabular}

\section{Discussion}

\subsection{Currents}

The results present some clear trends relevant to the impact of benthos on sediment motion.

Even when longitudinal, $x$ velocities are being damped by the presence of the array (Fig. 5), turbulent kinetic energy, $k=\frac{1}{2}\left(u^{\prime 2}+v^{\prime 2}+w^{\prime 2}\right)$, is generated within the cylinder array (Fig. 6), enhancing the resuspension process and accelerating the onset of sediment transport, consistent with the findings of Sumer et al. (2003), who observed significant increases in sediment transport if they increase turbulence levels while keeping the same flow speeds.

For the denser cases, even at low speeds, scour begins to occur, the wake behind each cylinder contributes to lifting the sediment, interacting with the adjacent wakes and the reduced current, allowing for the sediment to stay in suspension for the instruments to capture. Nepf and Koch (2013) observed a similar behaviour, with vertical secondary flows generated by vertical pressure gradients behind obstructions protruding from the bottom of a rigid bed. Comparing Figs. 5 and 6, it is apparent that neither the mean flow speed, nor the turbulent kinetic energy, are solely responsible for the resuspension: looking at Fig. 5 (right), lower values of $k$ are required to reach similar values of $C$ at $n=150 \mathrm{~m}^{-2}$ than at $n=250 \mathrm{~m}^{-2}$, consistent with velocities within the $n=150 \mathrm{~m}^{-2}$ array higher than those within the densest one. Follett and Nepf (2012) also noted the competing effect between the reduced velocities and increase of turbulent production as the density increases, resulting in increased scour at higher densities, concluding that given the small size of their patch $(<0.22 \mathrm{~m})$, it behaved as the leading edge of a 

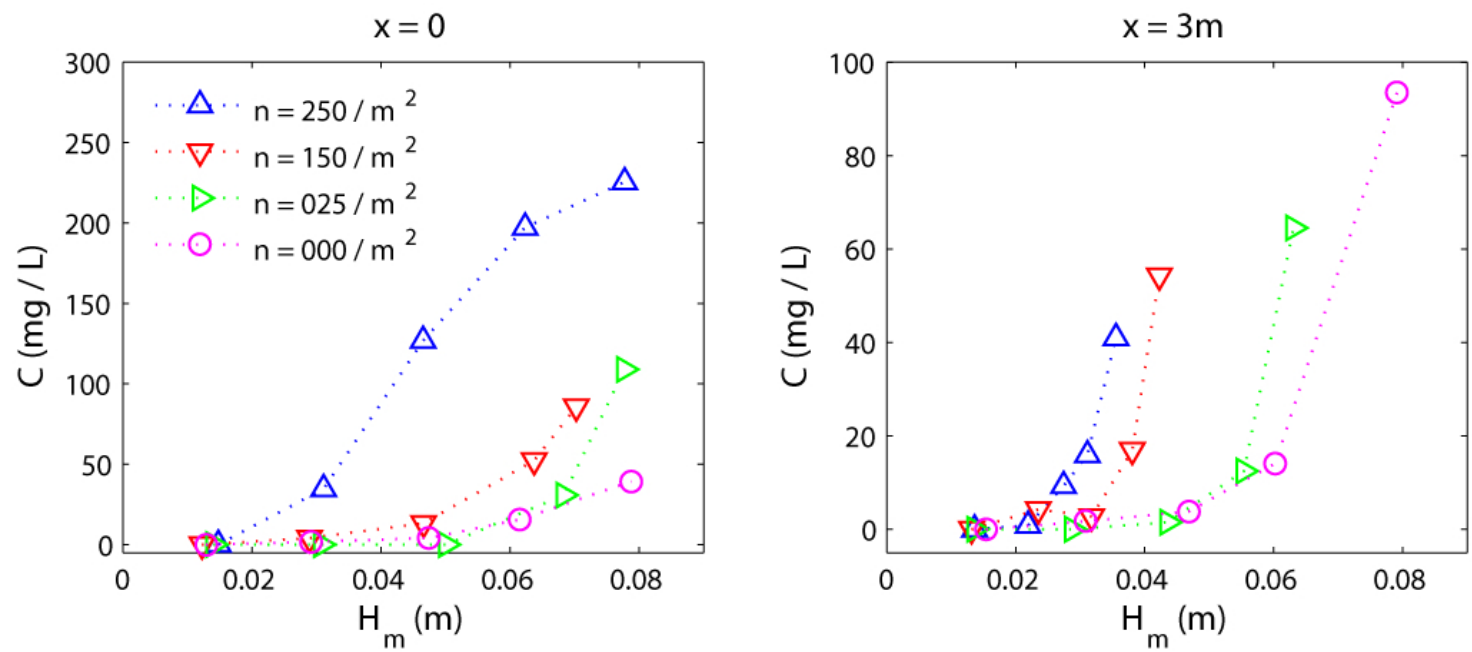

Figure 11. Mean concentrations against measured mean wave heights for all densities at two instrumented locations. Notice the different vertical scales.
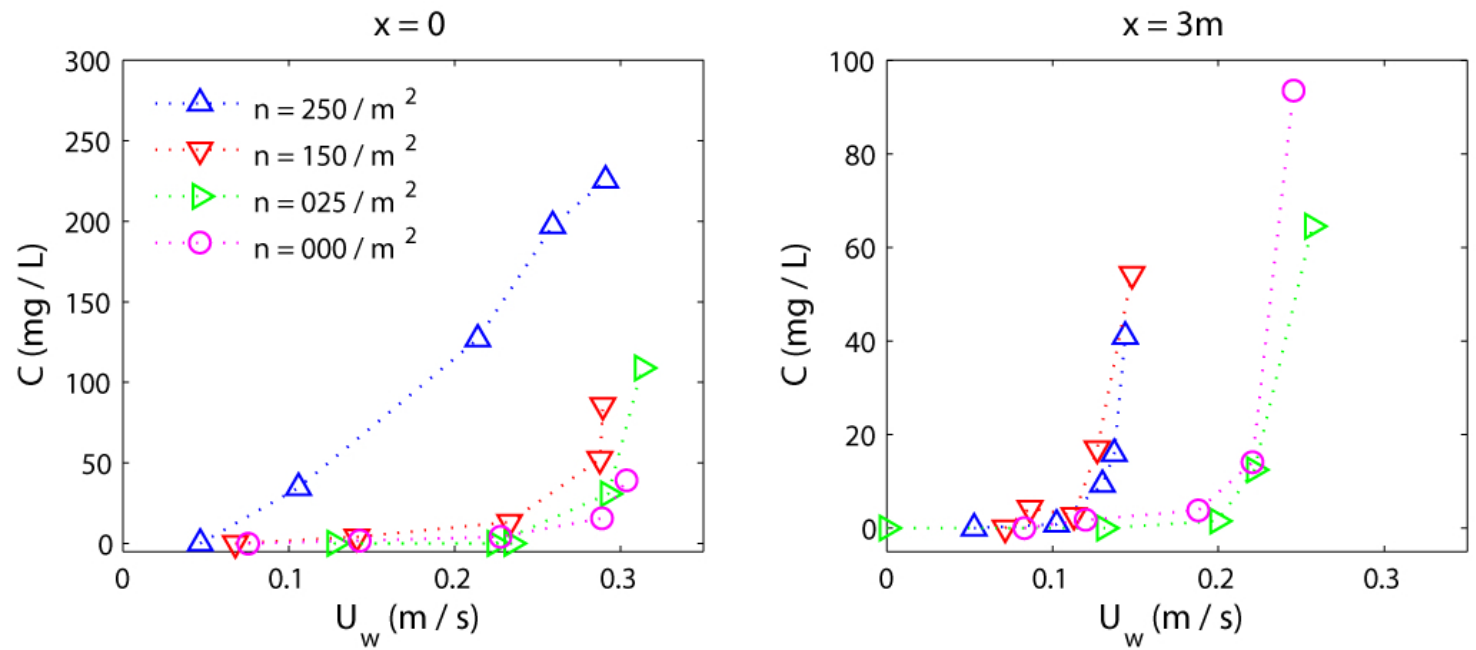

Figure 12. Mean concentrations against measured near-bottom orbital speed for all densities at two instrumented locations. Notice the different vertical scales.

longer patch. However, our measurements at the middle of our array, where fully developed flow is expected, continue to show the same increase in scour.

As a reference point, we can compare the threshold values obtained from the OBS readings (Table 3) against theoretical values from non-populated mobile beds (see Sect. 1.1). The determination of thresholds from experimental data can be a topic of discussion by itself. In our case, the thresholds were determined by finding the velocity at which the instrument starts recording concentrations higher than the background levels. The predicted values (Table 4) are considerably higher than the ones observed during the experiments, not only in the populated cases, where the cylinders clearly enhance sediment resuspension, but also in the smooth sand bed case, which can be explained either by irregularities in the flat initial conditions of the sand bed, or by the effect of the intrusive instrumentation deployed (steel rods protruding through the sand to hold ADVs and OBSs). The height of the measurements ( $5 \mathrm{~cm}$ above the bed) must also be considered, since the physical dimensions of the instruments prevent us from getting closer to the bed, where material could be already in suspension at lower elevations before the OBSs are able to record it.

\subsection{Waves}

Data presented in Figs. 11 and 12 hint at a density independence within certain density ranges. Madsen et al. (2001) found contradictory results in studies arguing whether or not density is a relevant parameter for velocity reduction. Our 

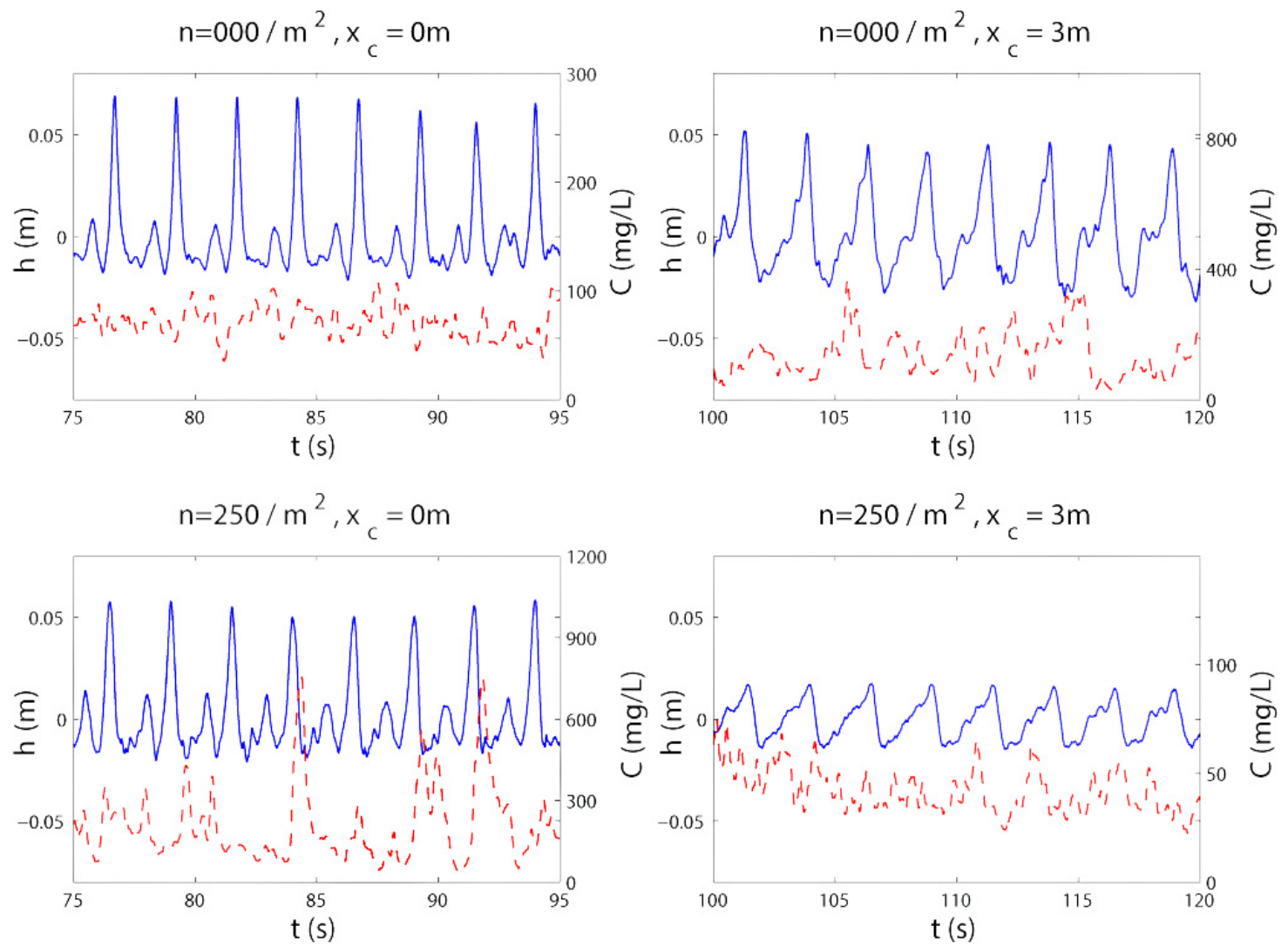

Figure 13. Time series of free surface elevation (blue solid line) and concentration (red dashed line) for the non-populated (up) and densest (down) cases, at locations $x_{\mathrm{c}}=0 \mathrm{~m}$ (left) and $x_{\mathrm{c}}=3 \mathrm{~m}$ (right), for waves $H=0.05 \mathrm{~m}$. Notice the scale for $\eta$ is conserved in all figures, while the scale of $C$ changes between figures.
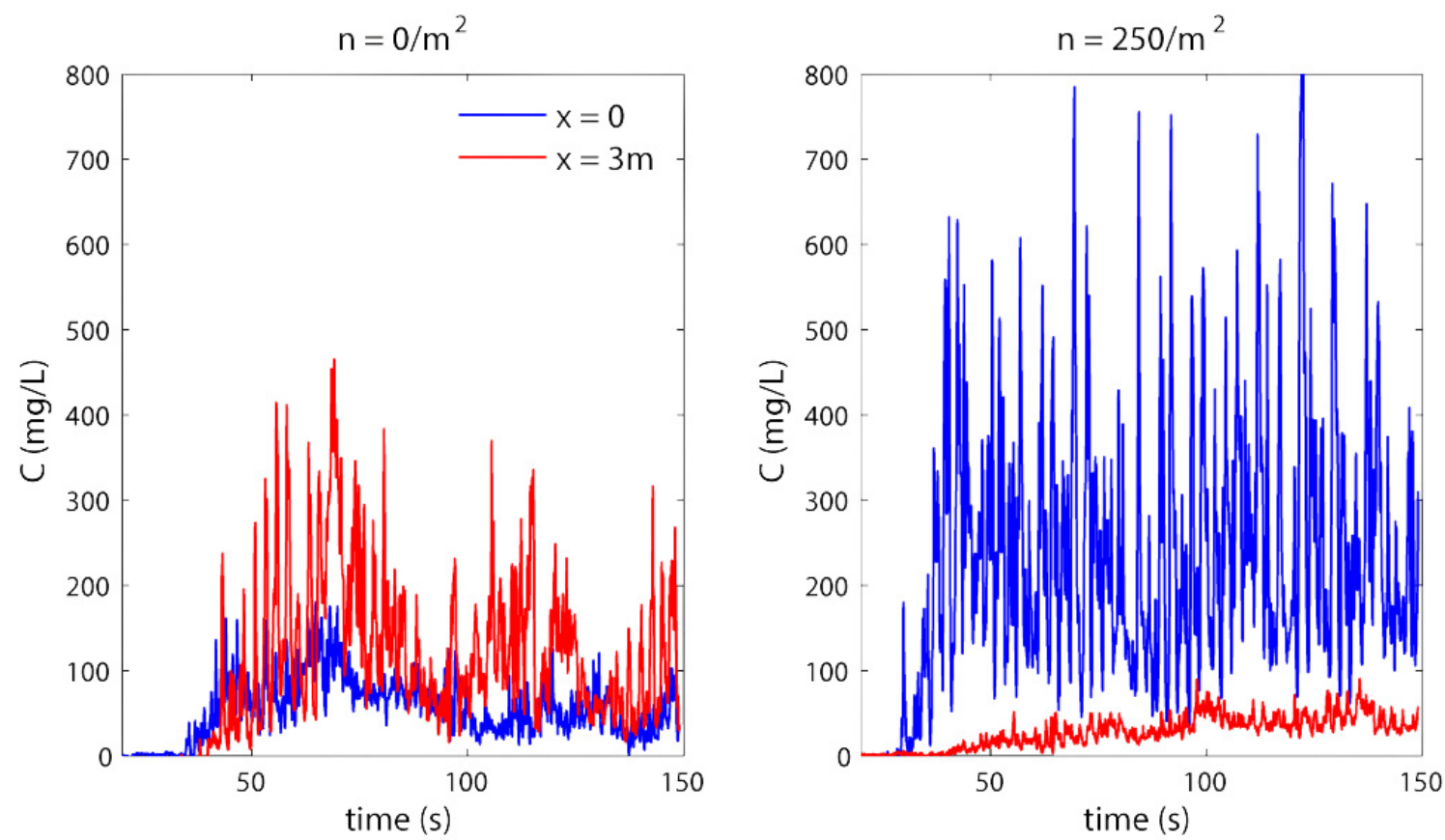

Figure 14. Time series of suspended sediment concentration for the non-populated (left) and densest (right) cases, at locations $x_{\mathrm{c}}=0 \mathrm{~m}$ and $x_{\mathrm{c}}=3 \mathrm{~m}$, for waves $H=0.05 \mathrm{~m}$. 

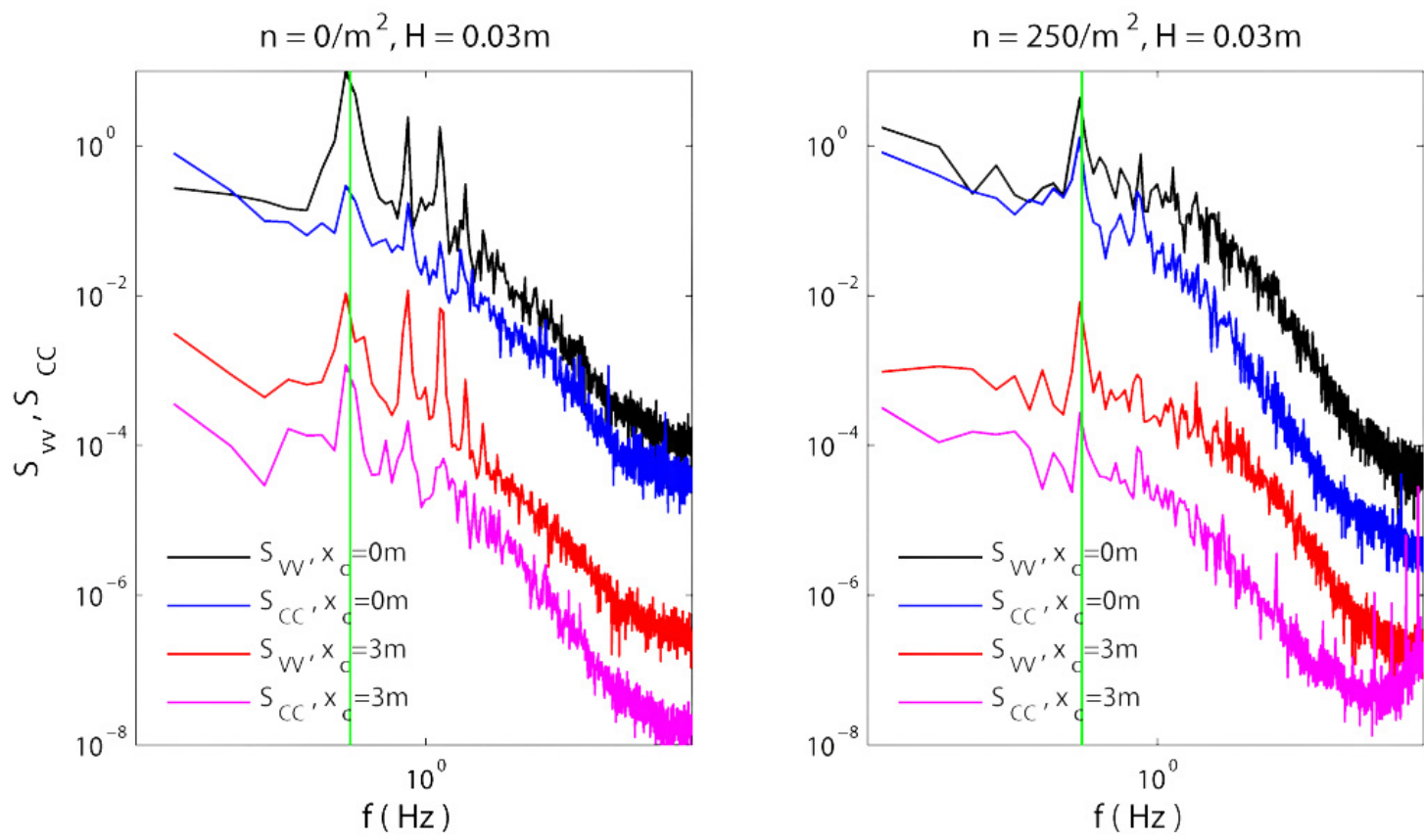

Figure 15. Frequency spectra of transverse velocity and concentration for the cases $n=0 \mathrm{~m}^{-2}$ (left) and $n=250 \mathrm{~m}^{-2}$ (right), at longitudinal locations $x_{\mathrm{c}}=0$ and $x_{\mathrm{c}}=3 \mathrm{~m}$. Vertical green line shows the considered wave period $T=2.5 \mathrm{~s}$. Actual amplitudes altered to improve visualisation.

data shows that (a) results depend significantly on the location of the measurement, and (b) density values within the same regime (sparse, intermediate or dense) can share similar behaviours, but the relevance of the density can not be overlooked (e.g. from Figs. 11 and 12, looking only at the results for $n=25$ and $150 \mathrm{~m}^{-2}$, the effect of density is clear, while looking only at the $n=250$ and $150 \mathrm{~m}^{-2}$ can mislead into conclusions of density independence).

The data presented in Fig. 12 allow us to estimate a critical orbital velocity for each density. We notice that an abrupt change in concentration is apparent for all cases at specific velocities, but the determined thresholds (velocities at which the concentration exceeds the background levels) occur at lower values. We compare those values, presented in Table 3, against the theoretical threshold, $U_{\mathrm{wc}}=0.112 \mathrm{~m} \mathrm{~s}^{-1}$ from Komar and Miller (1973) for non-populated mobile beds. The measured values for the sparse cases, $n=0$ and $n=25 \mathrm{~m}^{-2}$, agree with the predicted value, while the densest cases show a near $40 \%$ reduction of the critical velocity.

Additional effects of the array density were observed by looking at the spectra to investigate similarities between velocities and concentration records. Figure 15 shows two relevant features: (1) the presence of higher frequency harmonics in all cases, (2) the smoother spectra for the densest case, with none of the large peaks observed in the non-populated case, showing a redistribution of energy within the array, with more energy contained at smaller scales and higher frequencies, and (3) the same redistribution appears as we move from $x_{\mathrm{c}}=0$ to $x_{\mathrm{c}}=3 \mathrm{~m}$ through the array, with an evident shift in the energy cascade.

Madsen et al. (2001) found differences in the interactions between flow, vegetation and sediment, among regions dominated by either waves or unidirectional currents, finding contradictory results in (a) whether or not the density is relevant for velocity reduction, (b) if turbulence decreased or increased within vegetation, and (c) whether sediment resuspension is higher in wave-dominated areas than in tide-dominated ones. As pointed out through the present manuscript, one must be extremely cautious when comparing: (1) emergent and submerged conditions: the added mixing layer and the appearance of skimming flow in the submerged case produce contradictory results within the vegetation; (2) rigid and flexible model vegetation: plants bending under currents create a different and increased sheltering effect damping possible coherent structures that would appear on rigid structures, while the flapping of flexible vegetation under waves increases the bed exposition to the flow and changes the energy dissipation with respect to rigid element; or (3) laboratory and field studies: although density effects on resuspension have already been reported (e.g. Widdows and Brinsley, 2002), it is worth reiterating that biological interactions in the field between the organisms and the sediment can produce an effect contrary to the expected from their physical presence (e.g. plants roots or biofilms holding the sediment together). 


\section{Conclusions}

Arrays of randomly placed emergent cylinders, simulating benthic populations, change the flow-sediment interactions around and within the array.

The presence of arrays of rigid cylinders enhances sediment resuspension under waves and currents. The measured critical velocities for the densest cases are considerably smaller than those for the sparsest cases, and smaller than predicted velocities for non-populated beds.

With unidirectional currents, by slowing down the flow, emergent arrays might be expected to suppress bottom shear stress, reduce resuspension and favour deposition. However, the cylinder wakes enhance scour, the bed shear stresses change, and the increased turbulence levels within the array effectively enhance resuspension.

For the sparse cases under currents, the values of suspended sediment concentration begin to increase slowly when the threshold is reached, as opposed to the dense cases where once the threshold is reached there is an abrupt jump in such values.

For both waves and currents, eddies break down to smaller scales as they move through the array, with energy passing from wave scales to individual cylinder scales.

The density of the array is a determining parameter on the early onset of sediment resuspension. There is a clear distinction between the resuspension behaviour of sparse and dense arrays.

More studies are needed to further improve understanding and predictive capability of resuspension in these fragile environments.

Acknowledgements. The authors gratefully acknowledge the support of the Augusto Gonzalez Linares program at the University of Cantabria, and the comments of two anonymous reviewers to improve the manuscript.

Edited by: F. Metivier

\section{References}

Borsje, B., Kruijt, M., Werf, J., Hulscher, S., and Herman, P.: Modeling biogeomorphological interactions in underwater nourishments, Coast. Engineer. Proc., 1, 1-11, 2011.

Bouma, T., van Duren, L., Temmerman, S., Claverie, T., BlancoGarcia, A., Ysebaert, T., and Herman, P.: Spatial flow and sedimentation patterns within patches of epibenthic structures: Combining field, flume and modelling experiments, Cont. Shelf Res., 27, 1020-1045, 2007.

Carey, D.: Particle resuspension in the benthic boundary layer induced by flow around polychaete tubes, Can. J. Fish. Aquat. Sci., 40, 301-308, 1983.

Coco, G., Thrush, S., Green, M., and Hewitt, J.: Feedbacks between bivalve density, flow, and suspended sediment concentration on patch stable states, Ecology, 87, 2862-2870, 2006.
Eckman, J., Nowell, A., and Jumars, P.: Sediment destabilization by animal tubes, J. Mar. Res., 39, 361-374, 1981.

Follett, E. M. and Nepf, H. M.: Sediment patterns near a model patch of reedy emergent vegetation, Geomorphology, 179, 141151, 2012.

Fonseca, M. and Cahalan, J.: A preliminary evaluation of wave attenuation by four species of seagrasses, Estuar. Coast. Shelf Sci., 35, 565-576, 1992.

Friedrichs, M., Graf, G., and Springer, B.: Skimming flow induced over a simulated polychaete tube lawn at low population densities, Mar. Ecol.-Prog. Ser., 192, 219-228, 2000.

Graf, G. and Rosenberg, R.: Bioresuspension and biodeposition: a review, J. Marine Syst., 11, 269-278, 1997.

Green, M. O.: Test of sediment initial-motion theories using irregular-wave field data, Sedimentology, 46, 427-441, 1999.

Green, M. O.: Very small waves and associated sediment resuspension on an estuarine intertidal flat, Estuarine, coastal and shelf science, 93, 449-459, 2011.

Hoefel, F. and Elgar, S.: Wave-induced sediment transport and sandbar migration, Science, 299, 1885-1887, 2003.

Houck, M. and Neill, R.: Plant fact sheet for black mangrove (Avicennia germinans (L.) L.), Tech. rep., USDA-Natural Resources Conservation Service, Louisiana Plant Materials Center, 2009.

Infantes, E., Orfila, A., Simarro, G., Terrados, J., Luhar, M., and Nepf, H.: Effect of a seagrass (Posidonia oceanica) meadow on wave propagation, Mar. Ecol.-Prog. Ser., 456, 63-72, 2012.

Kobayashi, N., Raichle, A., and Asano, T.: Wave attenuation by vegetation, J. Waterway, Port, Coastal, Ocean Eng., 119, 30-48, 1993.

Komar, P. D. and Miller, M. C.: The threshold of sediment movement under oscillatory water waves, J. Sediment. Petrol., 43, 1101-1110, 1973.

LeHir, P., Monbet, Y., and Orvain, F.: Sedimenr erodability in sediment transport modelling: Can we account for biota effects?, Cont. Shelf Res., 27, 1116-1142, 2007.

Luckenbach, M.: Sediment stability around animal tubes: The roles of hydrodynamic processes and biotic activity, Limnol. Oceanogr., 31, 779-787, 1986.

Madsen, J., Chambers, P., James, W., Koch, E., and Westlake, D.: The interaction between water movement, sediment dynamics and submersed macrophytes, Hydrobiologia, 444, 71-84, 2001.

Maza, M., Lara, J., and Losada, I.: A coupler model of submerged vegetation under oscillatory flow using Navier-Stokes equations, Coast. Eng., 80, 16-34, 2013.

Nepf, H.: Flow and transport in regions with aquatic vegetation, Annu. Rev. Fluid Mech., 44, 123-142, 2012a.

Nepf, H.: Hydrodynamics of vegetated channels, J. Hydraul. Res., 50, 262-279, 2012b.

Nepf, H. M. and Koch, E. W.: Vertical secondary flows in submersed plant-like arrays, Limnol. Oceanogr., 44, 1072-1080, 1999.

Nikora, V.: ydrodynamics of aquatic ecosystems: an interface between ecology, biomechanics and environmental fluid mechanics, River Res. Appl., 26, 367-384, 2010.

Soulsby, R.: Dynamics of marine sands, Thomas Telford Publications, 1997.

Sumer, B., Chua, L., Cheng, N., and Fredsoe, J.: Influence of turbulence on bed load sediment transport, J. Hydraul. Eng., 129 585-596, 2003. 
Tinoco, R. and Cowen, E.: The direct and indirect measurement of boundary stress and drag on individual and complex arrays of elements, Exp. Fluids, 54, 1-16, 2013.

van der A,D.A., O’Donoghue, T., and Ribberink, J.S.: Measurements of sheet flow transpor $t$ in acceleration-skewed oscillatory flow and comparison with practical formulations, Coast. Eng., 57, 331-342, 2010.

VanHoey, G., Guilini, K., Rabaut, M., Vincx, M., and Degraer, S.: Ecological implications of the presence of the tube-building polychaete Lanice conchilega on soft-bottom benthic ecosystems, Mar. Biol., 154, 1009-1019, 2008.
VanRijn, L.: Sediment transport, Part II: Suspended load transport, J. Hydraul. Eng., 110, 1613-1641, 1984.

VanRijn, L.: Unified view of sediment transport by currents and waves. I: Initiation of motion, bed roughness, and bed-load transport, J. Hydraul. Eng., 133, 649-667, 2007.

Wallentinus, I. and Nyberg, C.: Introduced marine organisms as habitat modifiers, Mar. Pollut. Bull., 55, 323-332, 2007.

Widdows, J. and Brinsley, M.: Impact of biotic and abiotic processes on sediment dynamics and the consequences to the structure and functioning of the intertidal zone, J. Sea Res., 48, 143-156, 2002. 